force was found, indicates the possibility of a transition interval for these carbons.

The author's thanks are due his assistant, Mr. J. B. Davies, for much of the painstaking experimental work involved, and Mr. W. R. Mott for aid in looking up the literature.

Rgsearch I,aboratory, National, Carbon Co., Clethland, Ohto.

\title{
A NEW CRYSTALIINE VARIETY OF SILVER.
}

by Tarini Charan Choddhri.

Received July 6, 1915.

Various modifications of silver, many of them of somewhat ill-defined character, have, from time to time, been described. ${ }^{1}$ Carey L,ea has carried out an extensive series of researches on the properties of silver precipitated from a solution of its salts by ferrous citrate, ferrous tartrate, etc., in the presence of alkalis. His colloidal silver, which is held to be an allotropic modification of the metal, displays almost every shade of color-blue, red, green, purple and golden; some of his "precipitates" are very soluble in water and very sensitive to light. According to Lüdkte, ${ }^{2}$ however, the mirror and the black silver, obtained by the reduction of silver nitrate with zinc, are allotropic modifications, while the work of Kohlschütter and Fischmann is an attempt to explain the way in which the specular form of native silver, known as hair-silver, is formed.

\section{Experimental.}

Spongy silver ${ }^{3}$ was first prepared by igniting pure and dry precipitated silver tartrate in a crucible. Nitric acid, diluted with an equal volume of water, dissolved the silver completely. Strong nitric acid (sp. gr. I.42), however, from which lower oxides of nitrogen were removed by boiling with carbamide, was allowed to act on the spongy silver at the ordinary temperature. At first some action took place with the formation of silver nitrate, nitrous acid and oxides of nitrogen; but after a time the solution of silver stopped, and on allowing the mixture to stand with occasional shaking for about a fortnight, the remaining silver was converted into long needle-shaped crystals-easily visible to the naked eye.

At first a few thin, needle-shaped crystals appeared floating on the surface of the acid liquid which was being shaken; the test tube being allowed to stand again for some time, the crystals gradually increased in quantity, the larger needles remaining at the bottom of the tube. The nitric acid was decanted off and the crystals were thoroughly washed with

${ }^{1}$ Carey Lea, $A m$. J. Sci., 37, 476; 38, 47, I29 (1889); Phil. Mag., 31, 238, 320, 497; 32, 337 (1891); Am. J. Sci., 48, 343 (1894); Lüdtke, Wied. Ann., 92, 152, 1056 (1894); Kohlschütter and Fischmann, $A n n ., 387,86$ (1912).

2 Wied. Ann., 50, 678 (1883).

3 The spongy silver examined under the microscope showed no crystalline structure. 
distilled water. They had the characteristic white metallic lustre of silver and belonged to the cubic system. The following experiments show that the crystals are nothing but metallic silver:

(I) A weighed quantity of the crystals was heated on a small cupel in a muffle furnace and the button of silver obtained was weighed:

$$
0.1370 \text { gave } 0.136 \mathrm{I} \mathrm{Ag}: \mathrm{Ag}=99.34 \% \text {. }
$$

(2) A weighed quantity was dissolved in moderately strong nitric acid and the silver precipitated and weighed as silver chloride:

$$
0.2840 \text { gave } 0.2826 \mathrm{AgCl}: \mathrm{Ag}=99.50 \% \text {. }
$$

This is considered to be a new variety of crystalline silver. Ordinary metallic silver consists of rhombic plates ${ }^{1}$ which, however, in form and in the mode of formation are quite different. Kohlschütter and Fischmann have described a variety termed hair-silver, but they have only been able to obtain this from silver sulfide or selenide at temperature of about $400^{\circ}$.

\section{Bearing on the Dynamic Theory of Allotropy.}

It has been observed, as referred to before, that the tiny needle-shaped crystals which were first formed, appeared on the surface of the column of liquid, so that the crystalline silver does not (at the moment of formation) co-exist with the spongy silver at the bottom of the vessel. It has also been observed that the spongy silver at the bottom gradually crumbles into a finer state of division, looking amorphous under the microscope, and this gradually diminishes in quantity, giving rise to crystalline needles at the surface.

As the conversion of spongy silver into crystalline variety takes place at the ordinary temperature in a heterogeneous system, Smits' dynamic theory of allotropy is not applicable to the present case. According to Smits, the transformation of one form into an allotrope is not a sudden process and at the high transformation temperature $(e . g$. , of rhombic sulfur into monoclinic and vice versa) each variety is partially miscible in the other at the high transition-temperature, and equilibrium, according to him, being established between different proportions of the different varieties. Benedict also holds somewhat similar views. But such ideas are evidently not applicable to the present case. Tammann's view however, applies better. According to him, allotropic change is due to difference in atomistic arrangements, and it is probable in the present case that, the solution-tension of metallic silver at the particular condition being small, the particles of silver, which are first produced from spongy silver, are drawn up by the capillary force of the liquid column to its surface where they orient themselves regularly in a different space-lattice, giving rise to the beautiful needles.

1 Hiorns' "Metallography:" Silver. 


\section{Summary.}

Spongy silver, prepared by igniting pure silver tartrate, was treated at the ordinary temperature with strong nitric acid (sp. gr. 1.42) from which lower oxides of nitrogen had been removed by boiling with carbamide. At first some action took place with the formation of silver nitrate and nitrous acid, but after a time the solution of silver stopped, and on allowing the mixture to stand with occasional shaking for about two weeks, the remaining silver was converted into long needle-shaped crystals easily visible to the naked eye; slender needles which are first formed, appear floating on the surface of the acid liquid. This is considered to be a new variety of crystalline silver, belonging to the cubical system.

The author desires to express his indebtedness to his professor, Dr. E. R. Watson, who took an active interest in course of this work.

Chemical Laboratory, Government Collega,

Dacca, Bengal (INDiA).

[CONTRIBUTION FROM THE ChEMICAL LABORATORY OF THE UNIVERSITY OF Michigan.]

\section{CAN THE DISSOCIATION THEORY BE APPLIED TO SOLID SOLUTIONS IN STEELS?}

By Edward D. Campeeli.

Received June 19, 1915.

The conception that many metals and alloys might be regarded as solidified solutions, either of miscible liquids or of compounds in solution, was clearly pointed out more than fifty years ago by A. Matthiessen. ${ }^{1}$ Under this conception pure or nearly pure metals and alloys would be regarded as liquids or mixtures of liquids, differing from ordinary ones only in viscosity, but still being solutions in which the atomic relations existing between solutes and solvent do not differ fundamentally from the same relations in ordinary solutions. Matthiessen made numerous measurements on the conductivity of metals and alloys but drew no general conclusions as to the relation between chemical constitution and electrical properties.

Some twenty years later, Barus and Strouhal ${ }^{2}$ carried on a long series of very careful experiments to show the relation existing between the hardness of tool steel and its electrical properties. The changes in specific resistance in tool steel induced by sudden quenching and reheating to various temperatures for different lengths of time were carefully investigated, but apparently no definite connection between change in specific resistance and chemical constitution was pointed out.

${ }^{1}$ Report of the British Association for the Advancement of Science, 1863, p. 37.

2 U. S. Geological Survey, Bull. 14, 1885. 